\title{
Preface to the special issue "Open Science for earth remote sensing: latest developments in software and data"
}

\author{
Francesco Pirotti ${ }^{1 *}$, Markus Neteler ${ }^{2}$ and Duccio Rocchini ${ }^{3,4}$
}

Open source (OS) has gone a long way since it started evolving as an alternative solution that uses communitybased development backed by research institutions and companies. Today numerous OS software for processing geospatial data are available and widely used. The "open" paradigm has spread also to standards and data, which are now often available as open data (OD) [1]. Another characteristic of OS is a pervasive community that provides tremendous support to research, development and to everyday work of end-users by pushing the evolution of OS tools [2] and providing feedback via mailing lists and forums. The corresponding advantages in the science of Earth Observation (EO) [3] has motivated this special issue (SI), "Open Science for Earth Remote Sensing: latest developments in software and data". ${ }^{1}$ In this SI, the reader will find descriptions of dedicated OS software and cutting-edge practical examples of solutions to problems related to EO. Contributions describe software and report investigations on methods related to remote sensing classification, photogrammetry, laser scanning processing and change detection. In the following sections, we report a brief summary of the contents.

Contributions $[4,5]$, relate an investigation on digital image analysis using principal component analysis (PCA) based on singular value decomposition (SVD) for detection of burned areas. The first part is theoretical, the second part is a practical application of the method using imagery from MODIS sensor satellite data and OS tools, i.e. GRASS GIS, QGIS, and R. Authors provide proof that uncentered and unscaled SVD may improve the spectral separability of burned areas in some of the higher order components.

Remote sensing data are growing exponentially in variety, volume and velocity, due to more satellites being sent into orbit and more sophisticated sensors that

\footnotetext{
* Correspondence: francesco.pirotti@unipd.it

1 University of Padova, Padova, Italy

Full list of author information is available at the end of the article
}

provide higher resolution [6]. Close range sensing from remotely piloted aircraft systems (RPAS) commonly deliver high volumes of data by providing very-high resolution imagery. It is nowadays common to have very large datasets in photogrammetry; authors in [7] present algorithms that can improve the workflow, and they discuss bottlenecks and solutions to reduce computational time. In paper [8] authors use data from RPAS to compare accuracy of machine learning algorithms for classification. They also discuss the impact of data size on training and classification steps. Laser scanning is also becoming a common data-rich source. It provides information on both horizontal and vertical domain. In particular it allows profiling high vegetation thanks to multiple reflections [9]. It also delivers high volumes of data in the form of point clouds [10]. Authors in [11] take fullest advantage of this technology and report their application to an ecological landscape indicator, the fragmentation index, which they extend to the 3D realm using airborne laser scanning data. Change detection is one of the fundamental applications of RS and authors in [12] provide an investigation on using a specific procedure to monitor change related to desertification. The authors' semi-automatic method provides amelioration with respect to unsupervised approaches.

Three software articles in this SI provide an overview and insights in specific software. Orfeo-Toolbox, a popular tool dedicated to digital image analysis, is thoroughly described in [13]. OpenDragon is a remote sensing educational platform with an integrated programming toolkit; the article by the developers in [14] provides insights on its applications for teaching. Photogrammetric methods allow the creation of 3D models from imagery; aspects of the structure from motion and image dense matching problems are implemented in MicMac and discussed in [15].

By no means has this SI pretended to be a complete overview of the numerous OS software and solutions that are available nowadays; this SI, in line with the 
objectives of the journal of Open Geospatial Data, Software and Standards, wants to stimulate to give recognition to the many ways OS has and keeps contributing to geospatial data analysis [16]. It is the editors' motivation to increase support and visibility of research, development and, in general, efforts towards motivating the scientific community to benefit the most from open solutions.

\section{Endnote}

${ }^{1}$ https://link.springer.com/journal/40965/topical Collection/AC_2e95924270638072d6d5f03b92fd6deb

\section{Publisher's Note}

Springer Nature remains neutral with regard to jurisdictional claims in published maps and institutional affiliations.

\section{Author details}

${ }^{1}$ University of Padova, Padova, Italy. ${ }^{2}$ Mundialis GmbH \& Co. KG, Bonn, Germany. ${ }^{3}$ University of Trento, Trento, Italy. ${ }^{4}$ Fondazione Edmund Mach, San Michele All'adige, Italy.

Received: 4 October 2017 Accepted: 4 October 2017

Published online: 25 October 2017

References

1. Rocchini D, Petras V, Petrasova A, Horning N, Furtkevicova L, Neteler M, et al. Open data and open source for remote sensing training in ecology. Ecol Inform. 2017:57-61. Available from: https://doi.org/10.1016/ jecoinf.2017.05.004.

2. Neteler M, Bowman MH, Landa M, Metz M. GRASS GIS: A multi-purpose open source GIS. Environ. Model Softw [Internet]. 2012;31:124-30. Available from: http://dx.doi.org/10.1016/j.envsoft.2011.11.014. [cited 23 May 2014]

3. Piragnolo M, Masiero A, Fissore F, Pirotti F. Solar irradiance Modelling with NASA WW GIS environment. ISPRS Int J Geo-Inf [Internet]. 2015;4:711-24. Available from: http://dx.doi.org/10.3390/ijgi4020711.

4. Alexandris N, Gupta S, Koutsias N. Remote sensing of burned areas via PCA, part 1; centering, scaling and EVD vs SVD. Open Geospat Data Softw Stand [Internet]. 2017;2:17. Available from: http://dx.doi.org/10.1186/s40965-017-0028-1

5. Alexandris N, Koutsias N, Gupta S. Remote sensing of burned areas via PCA, part 2: SVD-based PCA using MODIS and Landsat data. Open Geospat Data Softw Stand [Internet]. 2017;2:21. Available from: http://dx.doi.org/10.1186/ s40965-017-0029-0.

6. Mondello C, Hepner G, Medina R. ASPRS ten-year remote sensing industry forecast - phase V. Photogramm Eng Remote Sensing [Internet]. 2008;74: 1297-305. Available from: https://utah.pure.elsevier.com/en/publications/ asprs-ten-year-remote-sensing-industry-forecast-phase-v.

7. Martinez-Rubi O, Nex F, Pierrot-Deseilligny M, Rupnik E. Improving FOSS photogrammetric workflows for processing large image datasets. Open Geospat Data Softw Stand [Internet]. 2017:2:12. Available from: http://dx.doi.org/10.1186/s40965-017-0024-5.

8. Piragnolo M, Masiero A, Pirotti F. Open source R for applying machine learning to RPAS remote sensing images. Open Geospat Data Softw Stand [Internet]. 2017;2:16. Available from: http://dx.doi.org/10.1186/s40965-017-0033-4.

9. Pirotti F. Analysis of full-waveform LiDAR data for forestry applications: a review of investigations and methods. iForest - Biogeosciences For. 2011;4:100-6. Available from: http://dx.doi.org/10.3832/ifor0562-004

10. Pirotti F, Kobal M, Roussel JR. A comparison of tree segmentation methods using very high density airborne laser scanner data. ISPRS - Int Arch Photogramm Remote Sens Spat Inf Sci [Internet]. 2017;XLII-2/W7:285-90. Available from: http://dx.doi.org/10.5194/isprs-archives-XLII-2-W7-285-2017

11. Petras V, Newcomb DJ, Mitasova H. Generalized 3D fragmentation index derived from lidar point clouds. Open Geospat Data Softw Stand [Internet] 2017;2:9. Available from: http://dx.doi.org/10.1186/s40965-017-0021-8.

12. Zanchetta A, Bitelli G. A combined change detection procedure to study desertification using opensource tools. Open Geospat Data Softw Stand [Internet], 2017:2·10. Available from: http://dx doi.org/10.1186/ s40965-017-0023-6.
13. Grizonnet M, Michel J, Poughon V, Inglada J, Savinaud M, Cresson R. Orfeo ToolBox: open source processing of remote sensing images. Open Geospat Data Softw Stand [Internet]. 2017;2:15. Available from: http://dx.doi.org/ 10.1186/s40965-017-0031-6.

14. Rudahl K, Goldin SE. OpenDragon: software and a programmer's toolkit for teaching remote sensing and geoinformatics. Open Geospat Data Softw Stand [Internet]. 2017;2:7. Available from: http://dx.doi.org/10.1186/ s40965-017-0018-3.

15. Rupnik E, Daakir M, Pierrot DM. MicMac - a free, open-source solution for photogrammetry. Open Geospatial Data Softw Stand [Internet]. 2017;2:14. Available from: http://dx.doi.org/10.1186/s40965-017-0027-2.

16. Pirotti F, Brovelli MA, Prestifilippo G, Zamboni G, Kilsedar CE, Piragnolo M, et al. An open source virtual globe rendering engine for 3D applications: NASA world wind. Open Geospat Data Softw Stand [Internet]. 2017;2:4. Available from: http://dx.doi.org/10.1186/s40965-017-0016-5.

\section{Submit your manuscript to a SpringerOpen ${ }^{\circ}$ journal and benefit from:}

- Convenient online submission

Rigorous peer review

- Open access: articles freely available online

- High visibility within the field

- Retaining the copyright to your article

Submit your next manuscript at $>$ springeropen.com 